\title{
La reforma monetaria de 1905 y la flexibilización de los medios de pago en México
}

\section{The Monetary Reform of 1905 and the flexibility of payment methods in Mexico}

\author{
LUIS ANAYA MERCHANT \\ Universidad Autónoma del Estado de Morelos Center for US-Mexican Studies, UCSD
}

\begin{abstract}
RESUMEN
Este ensayo explora una fase importante en la evolución histórica del sistema monetario mexicano, haciendo hincapié en la relación entre su reforma de 1905 y el funcionamiento del sistema bancario. Además de revisar la literatura precedente, estudia la percepción de las autoridades mexicanas sobre la presunta inexorabilidad del patrón de cambio plata hacia el patrón de cambio oro, vinculándola tanto a los intereses nacionales como a coyunturas internacionales. Algunos de los problemas del retraso con el que se adoptó la reforma eran técnicos y para ser salvados se concibieron fondos de regulación que tuvieron un éxito inesperado, debido a fenómenos externos a su diseño. Este éxito pareció garantizar la flexibilidad del sistema monetario, sin embargo también pospuso la reforma del sistema financiero, lo que, aunado a las convicciones teóricas de los "reguladores", dejaría abierto el paso a nuevos canales de inestabilidad.
\end{abstract}

PALABRAS CLAVE: Reforma Monetaria, Plata, Instituciones Financieras, Porfiriato

Códigos JEL: N1, N2, N26

\section{ABSTRACT}

This essay explores an important phase in the historical evolution of the Mexican monetary system, stressing the relationship between its reformation of 1905 and the operation of the bank system. Besides revising previous literature, it also studies the perception Mexican authorities had of the presumed inexorability of the Silver Exchange Standard in relation to the Gold Exchange Standard, linking it as much to national interests as to the international situation. Some of the problems of the delay with which the reformation was adopted were technical and to solve them authorities created a regulation fund that had an unexpected success due to external phenomena. This success seemed to guarantee the flexibility of the monetary system; however it also postponed the reformation of the financial system. This delay in addition to the theoretical convictions of those "regulators" left open the way to new channels of uncertainty.

KEYWORDS: Monetary Reform, Silver, Financial Institutions, Porfiriato

JEL Codes: N1, N2, N26 


\section{Introducción ${ }^{1}$}

$\mathrm{L}$

a intención de contar con un tipo de cambio fijo pero flexible al crecimiento económico fue perseguida por el gobierno porfiriano con la transformación monetaria de $1905^{2}$. El objetivo central de este ensayo es analizar los límites de este cambio, principalmente en relación con la estructura bancaria que lo instrumentó. La reforma perseguía estabilizar la divisa mexicana —el peso- y dotar de mayor agilidad o flexibilidad a los medios de pago; un doble objetivo difícil de alcanzar dadas las contradicciones estructurales de la economía y las deficiencias del sistema bancario. Aunque el eje de análisis es la reforma de 1905, el trabajo transcurre en el marco temporal 1893-1907, pues éste propicia una mejor base de comprensión y permite enlazar con enfoques analíticos más amplios.

En México, la tendencia a generalizar un sistema mixto de pagos o de monedas con valor intrínseco y dinero bancario (billetes más depósitos), coincidió con un proceso de institucionalización bancaria con tendencias de concentración y segmentación. La creación de bancos comerciales de emisión estatales que acotaban la circulación fiduciaria a sus jurisdicciones afianzó una inercia histórica de segmentación de las economías provinciales ${ }^{3}$. La Ley General de Títulos y Operaciones de Crédito

[Fecha de recepción del original, 5 de marzo de 2009. Versión definitiva, 12 de abril de 2010]

1 Agradezco las críticas y sugerencias realizadas por los evaluadores externos, que me han permitido replantear algunas ideas importantes para el presente trabajo.

2 La historiografía denomina porfiriato a la dictadura ejercida por el General Porfirio Diaz Mori. Bajo el lema "orden y progreso", Diaz impulsó un proyecto modernizador autoritario sustentado en un fino equilibrio entre grupos de interés regional, aliados militares y políticos entre 1876 y1911 que implicó la reclusión, eliminación y cooptación de adversarios y el uso arbitrario de la fuerza pública. A pesar de carecer de los recursos fiscales básicos, de la infraestructura necesaria e incluso de legitimidad suficiente (su origen era una asonada militar), Díaz pudo establecer un gobierno que resolvió en lo fundamental estas tres áreas fundamentales. Para la estabilización del régimen fiscal porfiriano fue muy importante la producción argentífera doméstica, el restablecimiento del crédito internacional y la creación de un sistema bancario con estrechos lazos con París, Londres y Nueva York. México conocería una época de crecimiento económico, realineación de mercados regionales, industrialización, desarrollo de infraestructura (ferroviaria, urbana, etc.), flujos de inversión externa y una mayor capacidad exportadora soportada también en la depreciación de la plata y el favorable efecto producido porque la mayoría de los países industrializados hubiesen adoptado el patrón oro. Huelga advertir que ese modelo económico agudizó la desigualdad social que incubó el descontento revolucionario.

3 El carácter tardío del desarrollo mexicano se reflejaba en la evolución bancaria. A diferencia de Inglaterra, Francia y Estados Unidos o de la periferia europea, Alemania, Italia o España, el desarrollo del free banking mexicano fue esquivo y tuvo su mejor momento durante el azaroso proceso revolucionario. Anaya (2002a). Lamoreaux (1996) muestra como la ausencia de una legislación federal fuerte facilitó la espectacular multiplicación de los bancos locales norteamericanos que, pese a las diversas crisis financieras del XIX, no conoció procesos de consolidación similares a los ocurridos en Europa. El incipiente sistema mexicano se pareció más al alemán que a un modelo "típico" de banca libre, pues tampoco existía libertad de entrada al mercado (dependía de la discrecional autorización del Ministerio de Hacienda). Creó igualmente monopolios de emisión estatal pero, a diferencia de ése, las normas de supervisión del gobierno serían muy laxas. Anaya (2002b). Además, los montos nominales de entrada (capital social) eran altos, aunque posteriormente el capital efectivamente pagado en las instituciones fuera una fracción del primero. 
(1897) facilitó también una masiva emisión de billetes bancarios (más cercanos a los "pagarés al portador" o títulos de crédito actuales ${ }^{4}$ ) que circularon bajo un doble principio: el del privilegio de la circulación nacional y el acotado a la circulación subnacional. En efecto, dos bancos, el Nacional de México y el de Londres y México, emitían billetes privilegiados con la circulación nacional, mientras a los veintisiete bancos restantes se les privó de tal posibilidad. En ambos casos, la aceptación ocurría mediante un descuento que - en la práctica - los privilegiados, y en especial el primero, eludían por medio de sus sucursales ${ }^{5}$. El hecho de que las emisiones se exceptuaran fiscalmente por la citada ley incentivó el aumento de circulante, pero la caída de la plata dificultaba también la certeza de su valor, así como el deseo del legislador de equilibrar los intereses de los banqueros con el Estado y el comercio en general. El marco de excepciones que los regía (que incluía restricciones al uso del término "Banco") tenía como garantía legal clave de estabilidad, su convertibilidad en dinero (léase, moneda metálica), fundada en las reservas de los bancos emisores. Debe notarse que el proceso formativo de la banca ocurrió entre una población habituada a una circulación monetaria rígida, donde la difusión y penetración de la moneda — sobre todo la de baja denominación- era demasiado imperfecta ${ }^{6}$. Ocurría en un escenario de herencias coloniales vivas, donde los experimentos liberales decimonónicos por crear una moneda menuda que facilitara la circulación habían fracasado y en el que existían continuas sangrías de circulante ${ }^{7}$.

La oportunidad de nuevos negocios en el porfiriato cambiaría ese estado de cosas y sentaría las bases para mejorar la aceptación de los billetes bancarios; la que debe observarse con atención, al relacionarse con la masa metálica de respaldo. La relación entre circulante y crecimiento económico porfiriano presenta complicaciones porque la depreciación de la plata introducía efectos mixtos, como inhibir importaciones y alentar exportaciones. Algo que no sucedió siempre de acuerdo a la teoría. Además del comercio internacional, el asunto afectaba a la diferencia entre el

4 De hecho la citada ley estableció en seis meses el tiempo promedio de circulación de los billetes, pues era el período límite para considerar que un crédito era de corto plazo. Esto se justificaba también porque la ley establecía la especialización en la actividad bancaria, correspondiendo a los bancos hipotecarios y a los refaccionarios conceder créditos de plazos mayores.

5 En otro contexto nacional muy probablemente los excesos de emisión habrían implicado la depreciación de las emisiones, la inmediata solicitud de su conversión y por tanto la contracción de la oferta monetaria. Pero en el ambiente oligopólico mexicano las quiebras de bancos emisores solo ocurrieron en 1907 y la conducta del mercado no fue la señalada por la teoría, véase Anaya (2002b).

6 A decir de Cerda (1997), la oferta monetaria crecía más rápido que el PIB. Él define al periodo 1882-1900 como el de "más altas tasas de crecimiento de la emisión de dinero" y, añade, "de igual manera este periodo es el de mayor crecimiento de la moneda fiduciaria. Mientras que el crecimiento de la moneda en metálico fue de un 3,5\% anual, la moneda fiduciaria lo hizo a un ritmo de 21,5\%". Como se observa, diferencia entre "dinero" y "moneda fiduciaria", siendo así disociables en la integración de la oferta monetaria. Sin embargo, no parece incorporar los depósitos bancarios a la oferta monetaria. Romano (1998); Torres (1999) y Covarrubias (2000). 
valor nominal del peso y su valor intrínseco, y a la inflación. En el fondo se estimulaba al sector exportador con un tipo de cambio a la baja y una política liberal de precios internos; una combinación que atraería importantes flujos de capital internacional que alentaron el crecimiento, pero también mayores índices de desigualdad. De igual modo, la economía se hizo más sensible a las fluctuaciones de la plata, en tanto que el modelo de crecimiento frenaba la posibilidad de formar un mercado interno sólido que ofreciera mayores fuentes fiscales de ingreso y mejores plataformas de intercambio con el exterior.

Las fluctuaciones de la plata también afectaban al anclaje del sistema bancario de pagos, que recaía en última instancia sobre el dinero no bancario (moneda-metal). Después de todo, los poseedores de billetes bancarios confiaban poder convertirlos en "dinero" y era en esa operación de cambio donde descansaba la clave del funcionamiento de los bancos de emisión (obligados por ley a respaldar sus emisiones con una proporción de metálico). Claro, era de esperarse que la depreciación afectara su solidez, en razón de que los bancos debían respaldar el valor nominal de sus billetes con reservas metálicas depreciadas. Un par de preguntas podían derivarse de lo anterior: ¿Cuál era la dimensión del problema y cuáles sus efectos sobre los propósitos de la reforma?

\section{La historiografía y sus problemas}

La complicada evolución histórica de la circulación monetaria y los marcos institucionales que la regulan han sido objeto de continua reflexión de economistas e historiadores. Desde diversos ángulos han resaltado, por ejemplo, el papel que desempeñó la plata americana en el desarrollo histórico del dinero. La expansión capitalista o, si se prefiere, la formación del mercado mundial es incomprensible sin este elemento cohesionador trasladado a Europa y Asia (fuere como impuesto, botín, mercancía o medio de pago). Por más de tres siglos y hasta alcanzar sus mayores picos de producción, en el primer tercio del XIX, la plata americana facilitó la expansión del comercio internacional. Sin duda la Nueva España y, luego, el México republicano jugaron un papel central en ese proceso. Así, no obstante a sufrir altibajos, en 1900 México era el primer productor de plata del mundo con más del 30\% del total. Dada la importancia de esta cifra, era natural que la plata fuese la primera preocupación de la era porfiriana (1876-1911).

El primer registro de problemas vino con la agitada negociación de la denominada Deuda inglesa $(1883)^{8}$. Irónicamente, ésta abrió el paso para que regresara a la presidencia Porfirio Diaz. Cinco décadas después, ya consumada la revolución, los

Villegas (2005). 
viejos problemas reaparecerían aunados a retrocesos teóricos para replantear la pertinencia de rehabilitar la plata como patrón de cambio ${ }^{9}$. En buena medida era la subsistencia de un problema de largo aliento, insuficientemente resuelto por la reforma de 1905 y contra el que no existía ni memoria histórica ni bases teóricas consistentes a comienzos de la década de 1930.

Lo anterior llama la atención porque, aun considerando que faltan aspectos por aclarar de ésa reforma, no hay duda de que ha sido muy estudiada.

En primer término la discutieron sus actores y testigos, destacando el denominado "grupo de los científicos" porfirianos: Enrique Creel, Manuel Fernández Leal, Joaquín Casasús, Genaro Raigosa, Jaime Gurza, Pablo Macedo, Everardo Hegewisch, Enrique Martínez Sobral, José Iyves Limantour, etc. Funcionarios, banqueros, empresarios y abogados, entre otros miembros destacados de la inteligentsia liberal moderada del régimen. El debate tocó las implicaciones teóricas del problema, pero lo que más le preocupaba al stablishment porfiriano era su instrumentación económica y política. Sería en la discusión de cómo instrumentarla (formalizada en la Comisión Monetaria que estudió el problema) donde se manifestaron las divisiones e intereses contrapuestos en el interior del "grupo científico".

En segundo lugar, con un conocimiento más fragmentado, ideologizado y trabajos menos sistemáticos, pero de mayor enardecimiento político, la reforma fue criticada por opositores del régimen y representantes de intereses afectados por la depreciación, como Toribio Esquivel Obregón, Luis Cabrera, Rodolfo Nieto, etc.

Una tercera generación de estudiosos fue compuesta por asesores de intereses norteamericanos llegados a México durante la revolución: Walter E. Kemmerer, Walter McCaleb, Charles Conant, Edgar Turlington, Joseph Sterret, J. Stanclife Davies, Frank Tannenbaum, y otros.

Tiempo después, las sucesivas reformas monetarias de 1931 y 1932 replantearían la revisión de los alcances obtenidos en 1905 y generarían un debate circunscrito, en lo fundamental, a funcionarios y políticos: Alberto J. Pani, Luis Montes de Oca, David de la Fuente, Luciano Wiechers, Manuel Gómez Morín, etc. Sin embargo, estos últimos aprovecharon poco las experiencias de las generaciones porfirianas. La disrupción revolucionaria, la necesidad de distanciarse de los enemigos políticos y las nuevas circunstancias que siguieron a la gran depresión de 1929 los alejaron de la recuperación de sus experiencias.

Una quinta generación — que nos es contemporánea- de analistas e historiadores se ha ocupado de la reforma de 1905 dando lugar a dos líneas dominantes: la de la revisión de las ideas debatidas y la del análisis económico. Así, el trabajo de Luna

Con el término "rehabilitación" se implicaba su revalorización y la estabilización de la nueva equivalencia con el oro. Nos referimos, a las negociaciones de moratoria y rehabilitación del Congreso de Montevideo de 1932. 
y el ensayo pionero de Borja Martínez se inscriben en la primera línea; mientras que los de Cerda, Schell, Escalona y Musacchio se orientan más hacia la segunda.

\section{El problema y las causas de la baja de la plata}

El problema generado por la inestabilidad del valor de las monedas agobió a la mayoría de los gobiernos europeos y americanos durante el siglo XIX. En Europa se asignó tal importancia a la regularidad o "fijeza" de las variaciones de valor de la moneda que la cuestión rebasó ampliamente la esfera económica para afectar demandas del ámbito de la justicia y, consecuentemente, de los derechos de propie$\operatorname{dad}^{10}$. En síntesis, se puede afirmar que la peculiaridad central de la relación monetaria oro-plata durante el siglo XIX consistió en dos fenómenos:

1. entre 1800 y 1870 la relación oro-plata fluctuó moderadamente, situándose en el punto medio de la proporción 15,5 a 1, si nos atenemos a la proporción legalmente definida por el sistema bimetálico francés ${ }^{11}$;

2. a partir de 1870 la relación de intercambio se alteró hasta el punto de que la antigua heterogeneidad de sus manifestaciones cambió para siempre.

Es decir, de una situación longevamente estable se pasó a una de marcada inestabilidad. En paralelo, la mayoría de las economías europeas se inclinaron a sistemas monetarios basados en el "patrón oro", lo que implicó la tendencia a desmonetizar su plata. Desde luego, esto suscita varias preguntas: ¿qué causas motivaron el desplazamiento de la plata — pese a ser un sistema que mantuvo una relación estable con el oro durante más de tres siglos?, ¿cuáles fueron los efectos del cambio?, y, en esta línea de contraste causa-efecto, ¿hasta qué punto el caso mexicano se asemeja a otros procesos nacionales?

La primera pregunta, quizá la que más ha inquietado a los analistas, ha sido contestada siguiendo varias líneas de explicación. Destacan, entre ellas, la mayor baratura de la plata a partir de la segunda mitad del XIX (por descubrimientos de nuevos yacimientos y desarrollo de nuevos medios de explotación) y las políticas monetarias instrumentadas en los países europeos centrales (incluyendo las estrategias de sus agentes financieros); ambas líneas no se excluyen y se respaldan en una amplia evidencia empírica. También puede agregarse otra línea complementaria (poco tratada en la historiografía mexicana), la de la subvaluación del oro a lo largo de la primera mitad del XIX ${ }^{12}$.

\footnotetext{
Así lo planteó Walras (1896), p. 184.

Flandreau (1996).

Kemmerer (1947).
} 
Para esbozar la segunda cuestión pueden listarse acontecimientos significativos que agudizaron la baja de la plata. En 1871 ocurrió el primer evento destacable con la inconvertibilidad de los billetes del Banco de Francia; si bien el fenómeno era conocido por otros países (por ejemplo, Inglaterra, Italia y Estados Unidos) que atravesaron etapas de papel moneda depreciada, el caso fue peculiar para el futuro de la plata por la centralidad de Francia en el sistema bimetálico. Sobre todo porque, debido a su derrota ante Prusia, fue obligada a pagar indemnizaciones que facilitarían la transformación del régimen monetario alemán. Ese mismo año, Alemania adoptó su nueva unidad monetaria basada en el oro (el marco), y con esto inició la era de las transformaciones monetarias europeas.

Así, la adopción del patrón oro en Alemania fue resultado de su peculiar proceso de unificación política y de la posibilidad de financiar —al menos parcialmente- los costos de su transformación monetaria con recursos de las penas impuestas a Francia. La demanda alemana de oro fue exorbitante para el tamaño del mercado mundial: 50 millones de libras esterlinas ${ }^{13}$. Esta inusual demanda, que forzó los precios del oro al alza, coincidía - por razones obvias - con la inconvertibilidad en Francia, el país bimetálico por excelencia y en donde antes de la guerra el oro se obtenía libremente.

Si antes de 1873 sólo Inglaterra y algunos países bajo su influencia -Canadá, Australia, Chile, Egipto y Portugal- estaban en el patrón oro, con la decisión alemana el cambio europeo se precipitó: Suecia y Suiza en 1874, Francia y Bélgica en 1875, Italia en 1877 y, posteriormente, Holanda, Rusia y Austria-Hungría. Simultáneamente, pese a ser un gran productor del metal, Estados Unidos prohibió acuñar monedas de plata, lo que se interpretó como una transición hacia el patrón oro. El gobierno de Washington contrató empréstitos para estabilizar sus finanzas, pero el desorden monetario continuó y unos años después la Blind Allison Act obligó al secretario de Estado a comprar mensualmente de 2 a 4 millones de dólares en plata: parecía el regreso al bimetalismo. Sin embargo, la aparente vuelta se desdibujó cuando sobrevino la caída de la producción argentífera californiana, la suspensión de compras alemanas del metal y las cada vez más notorias fluctuaciones mercantiles que hacían menos rentable su explotación. Cuando Inglaterra clausuró sus Casas de Moneda de la India (1892), la suerte de los intereses plateros norteamericanos recibió otro importante revés, aunque las controversias y la agitación política en torno a la plata continuarían vivas, tal y como ocurría en Europa ${ }^{14}$.

Una lección de la experiencia europea de la década de 1870 fue la de afianzar un concepto monetario moderno, ya que en adelante el valor de las monedas no

\footnotetext{
13 Para el desequilibrio y la importancia que supuso esta cifra, véase el estudio de Eichengreen y Flandreau (1997).

14 Reti (1998).
} 
residiría en su contenido metálico. Pese a incertidumbres "teóricas" o lagunas de comprensión de la época, la lección reemplazaría las viejas ideas mercantilistas, en un proceso que se favoreció del mayor acceso a medios fiduciarios de pago. Incluso en Francia, la excepción importante ligada al sistema bimetálico, la resistencia a la transformación no se explicaba con argumentos contrarios a esta modernización, sino por razones pragmáticas: por el elevado costo de la transformación monetaria y por conservar colonias importantes donde los medios fiduciarios eran de difícil desarrollo ${ }^{15}$ (Cuadro 1).

Si en Europa este tránsito no se vivió con facilidad, en un país atrasado, tradicionalista y dependiente de la plata — como México - era esperable que fuese objeto de evaluaciones escépticas, mayores dilaciones y duras críticas. Pero ¿había la posibilidad de emplear el medio arriba señalado (crear dinero fiduciario) para cambiar el sistema bajo el contexto de la continua depreciación de la plata? Es decir, ¿si no se aprobaba el tránsito al patrón oro y se abandonaba el sistema de valor intrínseco de la moneda, podía recurrirse a la emisión de billetes como medio para acelerar la circulación de riqueza? La respuesta de la mayoría porfiriana era negativa, viendo ése medio con gran suspicacia y comparando sus debilidades con la propia caída de la plata. Así, aunque Joaquín Casasús, consejero del Ministro de Hacienda, temía repetir las experiencias de inconvertibilidad europeas y norteamericanas, anhelaba encontrar una ruta para flexibilizar el sistema monetario. En particular le preocupaba que continuase el escenario de elevación de precios (por la devaluación) sin aumento de "jornales y salarios" (de lo que hay evidencia para la mayoría de los sectores económicos durante el porfiriato); pues tal concatenación conducía a una crisis de subconsumo que desalentaba "la prosperidad de la producción nacional"16.

\section{1893: México y el problema internacional}

En este apartado revisamos las principales líneas de evaluación debatidas por los analistas mexicanos antes de la reforma y en especial su interés por la circunstancia norteamericana por dos razones: coordinar su política con los "defensores de la plata" en el vecino del norte y el interés por asimilar su experiencia en la materia ${ }^{17}$.

Infortunadamente, el anhelo de coordinar una política en favor del bimetalismo coincidió con la depresión de 1893. Durante ésta, Matías Romero y José Yves Liman-

\footnotetext{
15 CARSO, CDLIV, r. 19, Comission on International Exchange USA/Comisión de Cambios Internacionales México, junio de 1903.

16 Casasús (1905), p. 69.

17 Friedman (1990).
} 
tour, sucesivos secretarios de Hacienda, escudriñaron entre la clase política norteamericana buscando a quienes mostrasen proclividad por la libre acuñación del metal $^{18}$. Desplegaron gran actividad diplomática con norteamericanos y países de la Unión Latina en un intento de regresar a la era de estabilidad en los cambios internacionales. Sin embargo, al final de ese año, después de la inoperante Conferencia Monetaria de Bruselas y del fracaso de las medidas norteamericanas (evidenciadas con la suspensión de la Ley Sherman), Estados Unidos adoptaron el patrón oro, dejando a México como el mayor productor mundial de plata y, consecuentemente, como la nación americana más interesada en usarla como moneda y producto de exportación (representaba más del 50\% de los ingresos del erario).

En el anterior escenario y calculando la simpatía de los productores norteamericanos, Romero propuso celebrar una conferencia de los países de la Unión Latina para acordar medidas en favor de su acuñación monetaria ${ }^{19}$. El apoyo de Porfirio Diaz, el interés del gobierno japonés y la posibilidad real de que "los populistas" norteamericanos ganaran la presidencia, alimentaron buenos augurios. Sin embargo, los esfuerzos toparon con la indiferencia británica que, pese a las dudas abiertas por la inestable situación en India, rechazó la posibilidad de reabrir sus casas coloniales de moneda. En Alemania, aunque existía conciencia de haber actuado con precipitación al desmonetizar la plata, no se planteó modificar la situación. No extraña entonces que los aliados del proyecto mexicano surgieran de los denominados "populistas" norteamericanos, es decir, de entre los sectores mineros afectados por la desmonetización.

Por lo demás, entre los "populistas" surgieron comprensiones sesgadas del problema; por ejemplo, que la decisión inglesa era inspirada por la Casa Rothschild. Estas simplificaciones eran divulgadas por personajes como el senador William Stewart, corresponsal de Romero, quien las reproducía a Limantour y Diaz ${ }^{20}$. Así, los políticos mexicanos percibían que el patrón oro no obedecía a un proceso ineluctable, sino a uno frenable con contramedidas políticas. De aquí se explica que el gobierno porfirista viera con interés el crecimiento de la candidatura presidencial de William J. Bryan, quien abogaba por remonetizar la plata. A su vez, "los populistas" entendían la alianza con México como un importante apoyo a su causa.

\footnotetext{
18 “En el Congreso, así en el Senado como en la Cámara de Diputados hay mayoría en favor de la plata mientras que el Presidente y su gabinete están decididamente en contra. Esto hará que no se llegue a ningún acuerdo y que subsista la ley actual que impone al gobierno la obligación de comprar 4.500.000 onzas de plata cada mes, pues aunque los enemigos de ese metal se esforzarán por derogarla los partidarios de la plata procurarán sostenerla a falta de mayores concesiones"; CARSO, CDLIV, r. 12, Washington, M. Romero a JYL, abril 8, 1893.

19 Ibíd., Romero a Limantour, noviembre 8, 1893.

20 W. Stewart a M. Romero, febrero 28 de 1894, en CEH-CARSO, CDLIV, r. 19, y CARSO, CDLIV, r. 12, M. Romero a Limantour, marzo 15 de 1894.
} 
Quizá por la oposición "populista", el gobierno norteamericano colocó signos de entendimiento sobre la mesa. Su propuesta, debatida con atención y seriedad, consistió en ofrecer casas de moneda norteamericanas para acuñar pesos mexicanos. Años antes, en 1886, fue sugerida otra alternativa que el gobierno mexicano rechazó: la posibilidad de adoptar una moneda común con Estados Unidos. A pesar de que el peso gozó de curso legal en la Unión Americana hasta el primer lustro de 1870 y que la propuesta de 1894 matizaba la de 1886, México volvió a rechazar la propuesta, probablemente por el cuestionamiento implícito que se hacía a su soberanía monetaria.

En paralelo, la continua baja de la plata alentaba el aumento de su exportación, orientada principalmente a India y China. Esta circunstancia hizo pensar al gobierno mexicano que sería insuficiente su acuñación, "aún y cuando toda se exportara". Por esto y sosteniendo el doble objetivo de aumentar el consumo y sostener el precio, se evaluó la conveniencia de exportar plata norteamericana bajo el cuño del peso mexicano. El proyecto parecía realizable en tanto que ni India ni China aceptaban plata en barras por desconfianza hacia su ley y mostraban su preferencia histórica por la moneda mexicana. La idea era aún más atractiva si se reducían riesgos de operación y costos de acuñación, y redundaba en una alianza con los plateros norteamericanos.

Por otra parte, se sabía que el gobierno japonés acuñaba su nueva moneda de plata (que llamaría "yen") bajo un costo de acuñación del 1\%. También se sabía que en Hong Kong los ingleses planeaban acuñar una moneda con cargo al gobierno y libre de gasto para los dueños de la plata — como sucedía en Estados Unidos- Es decir, en México se conocían acciones de transformación monetaria donde los factores de racionalización adquirían más peso. El factor de minimización de costos crecía en importancia bajo el escenario de la tendencia decreciente del precio de la plata; era un factor de primer orden para la competencia del peso, cuyos costos de acuñación ascendían al $4 \%$ de su valor (o cuatro veces respecto del yen). Por ello, no extraña que la idea fuese seriamente analizada e incluso — como vimos— se planteó la alternativa de instalar una Casa de Moneda en Paso del Norte (actual Ciudad Juárez) para acuñar pesos con plata estadounidense. Esto acortaría gastos de transporte hacia San Francisco y posterior embarco a Asia. Finalmente estas ideas no fructificarían, pero ingleses, japoneses y filipinos sí materializaron sus proyectos de monedas de plata que circularon en Asia y que se convertirían en competidores del peso mexicano ${ }^{21}$. Claro, la mayor competencia se tradujo en menos compras y más retos. Sin embargo, estos nuevos retos eran de menor importancia frente al propósito chino de establecer su propio sistema monetario a comienzos del siglo XX.

$21 \quad$ Kemmerer (1916). 
Por otra parte, como sucedió en Estados Unidos, la caída del precio de la plata abarataba una amplia gama de productos de exportación, objetando su rentabilidad. El encarecimiento de importaciones, bonos y acciones ferrocarrileras - $y$ otros pagos en oro- había cuestionado el sistema monetario norteamericano, cuya transformación se retrasó por efecto de la Guerra de Secesión. Además (lo que no se repitió exactamente en México) la disminución de reservas áureas provocó que el gobierno emitiera bonos de deuda para obtener oro; una operación que produjo una importante especulación bancaria (en 1895 se emitieron 100 millones de dólares que sus bancos absorbieron con avidez). Ante lo cual -y con el respaldo de un importante movimiento político - regresar al patrón plata se presentó como una alternativa posible $^{22}$. Posibilidad que se diluyó en las elecciones de 1896, cuando McKinley derrotó a Bryan, afianzando el triunfo de los intereses industriales y proteccionistas ${ }^{23}$. Con un escenario de cambios arancelarios al alza en Estados Unidos, se volvió más difícil implementar una política internacional de "estabilización de los cambios internacionales" o buscar la elevación de los precios de la plata. Ello se complicó aún más con el anuncio de los descubrimientos de oro en Australia, Sudáfrica y Yukón. Toda una serie de reveses imprevistos que, sin duda, tendrían a México como uno de los países más afectados.

\section{El debate porfiriano o los problemas de reformar}

En sus múltiples fracasos para crear un frente contra el patrón oro, los porfirianos podían entender que tras la caída de la plata existían decisiones políticas que podían ser socavadas, sin embargo también aprendieron que su reticencia al cambio constituía una política cada vez más costosa. La persistencia de la depreciación forjaba la conciencia de que retrasar la homologación con el patrón oro implicaba desajustes más onerosos ${ }^{24}$ e implicaba continuar contraponiendo intereses y alimentar polémicas que dividirían el consenso hacia el régimen ${ }^{25}$. Para el comienzo del siglo xx existía más experiencia e información y, sobre todo, una mayor aceptación (o, resig-

22 CARSO, CDLIV, r. 12, Washington, M. Romero a Limantour, septiembre, 1895.

23 Para el peculiar proyecto arancelario con el que respondió México al arancel Dingley. Véase Riguzzi (2003).

24 Estas últimas se observan en el Código de Comercio de 1883 al tratar las obligaciones pecuniarias. El Código creó la "moneda certificada" para cubrir de la devaluación a los acreedores, obligando a los deudores a cubrir en moneda corriente la cantidad que correspondiese al valor real del débito. Llama la atención que en 1889, se reformara el precepto para cubrir tan sólo las sumas nominales adeudadas; algo que favorecía a los deudores en plata.

25 Hay ejemplos numerosos en la prensa de la época: La Semana Mercantil, El Economista Mexicano, El Imparcial, El Mundo, The Mexican Herald, etc. 
nación) de los sectores afectados por la depreciación ${ }^{26}$. Además, la fuerte presencia de inversionistas extranjeros en la minería de plata hacía que su influencia en la decisión del gobierno fuera más oblicua ${ }^{27}$.

Los argumentos en pro y en contra del cambio de patrón monetario evocaban los esgrimidos en Estados Unidos años atrás; para argumentar a favor se subrayaba el encarecimiento de la deuda (contratada en oro) y para hacerlo en contra se citaban sus efectos de protección en la economía y -lo que era diferente a Estados Unidosque el ingreso derivado de las exportaciones de plata no podía ser substituido por otra rama de la actividad económica. El reemplazo teórico era la agricultura, pero ésta era una pésima apuesta, como lo sabía la clase dirigente mexicana y lo constataban la mayoría de los periódicos al cuestionar la debilidad del "reemplazo", incluso en el hipotético caso de contar con grandes sistemas de irrigación ${ }^{28}$. Periódicos como $\mathrm{La}$ Semana Mercantil, El Mundo, El Imparcial, El Correo de Jalisco y El Economista Mexicano insistían en otro de los males consuetudinarios del porfiriato: la falta de trabajadores. Poco haría la irrigación sin ellos. Además, la falta de un sistema nacional de transporte marítimo encarecía los productos mexicanos y dificultaba su competencia.

Una nueva depresión de los precios de la plata en 1902 urgió a la Secretaría de Hacienda a revisar alternativas como la de aumentar los derechos de importación. $\mathrm{Al}$ presentar su iniciativa a las cámaras de comercio, Limantour argumentó que el aumento "repondría al erario de las cantidades que faltan para cubrir servicio de la deuda en oro y que no tendría efectos fuertes sobre el contribuyente" ${ }^{29}$. La medida obedecía a la depreciación porque, al contraer el intercambio comercial, contraía una parte importante de las recaudaciones. La medida de reequilibrio tenía un tono anacrónico, pues ya en 1896, en La cuestión de la plata, Casasús había advertido los problemas fiscales que la depreciación impondría al crecimiento económico. En 1902 los efectos eran acumulativos, pues la pretensión del nuevo impuesto derivaba de la vulnerabilidad de la balanza comercial, de las obligaciones externas del Estado y de su proyecto de fusionar las empresas ferrocarrileras. Más aún, antes de la caída de 1902 ya se percibía una etapa de fuerte oscilación en el precio del metal. Rosenzweig distinguió dos periodos: hasta 1899 fue uno de "franca caída", para después sobrevenir otro de "inestabilidad", que acentuó la incertidumbre de los cambios e hizo los cálculos improbables. El Cuadro 1 puede dar una mejor idea de los periodos:

\footnotetext{
26 Creel (1976), p. 81.

27 El número de propietarios extranjeros (principalmente norteamericanos, aunque también británicos y españoles) era mayor al de los mexicanos. Para esta importante presencia, véase Hanrahan (1985) y, a nivel regional, Hart (2008) y Ruiz (1998).

28 La Semana Mercantil (43), octubre 27 de 1902. El diario señalaba una característica crónica: "el cultivo hasta ahora ha sido pobre y rutinario". Habría además que mencionar las malas cosechas del final del siglo XIX y del comienzo del xx; véase Escobar (2004) y Cerda (1991).

29 La Semana Mercantil (44) noviembre 17 de 1902.
} 
CUADRO 1

VALOR DEL PESO MEXICANO, 1872-1905

\begin{tabular}{cc}
\hline Años & $\begin{array}{c}\text { Cotización en Nueva York } \\
\text { (centavos de dólar) }\end{array}$ \\
\hline 1872 & 1,001 \\
1878 & 0,910 \\
1883 & 0.882 \\
1888 & 0,759 \\
1893 & 0,657 \\
1898 & 0.448 \\
1899 & 0,472 \\
1900 & 0,476 \\
1901 & 0,488 \\
1902 & 0,441 \\
1903 & 0,398 \\
1904 & 0,441 \\
1905 & 0,483 \\
\hline
\end{tabular}

Fuente: Rosenzweig (1965), p. 866.

La combinatoria de depreciación e inestabilidad complicó el escenario. La caída afectaba por partida doble a las exportaciones: al influir directamente en el valor intrínseco del peso ( $y$, consecuentemente, del tipo de cambio) y porque al ser el primer producto de exportación, la devaluación de la plata deterioraba el valor conjunto de las exportaciones. Este doble efecto se desgranaba de distinto modo sobre los sectores económicos. El impacto más claro era la formación fáctica de una política proteccionista para los exportadores (sobre todo, de los que no importaban insumos), que se beneficiaban al vender sus productos a menores precios que los internacionales. En paralelo y dada la alza del oro, debieran haberse presentado decrementos significativos en las importaciones. Pero, la realidad no obedeció a la teoría y el ritmo de las importaciones se sostuvo, muy probablemente porque no podían ser sustituidas por productos mexicanos. En tal línea, Casasús deploró la escasez de datos oficiales y argumentó que pese a no "merecer entera fe y crédito" era "indudable que el aumento de nuestras importaciones del extranjero se ha llevado á cabo á pesar del alza de precios... que han subido enormemente y que han subido de una manera desproporcionada al alza de los cambios" ${ }^{\prime 30}$. Sus datos mostraban que, en una década, las importaciones aumentaron casi 50\%, lo que concuerda con investigaciones recientes ${ }^{31}$ (de 43,4 millones de pesos llegarían a 64,5 cotiza-

Casasús (1905), p. 52.

Carmagnani (1994), p. 305. 
dos en oro). Por lo demás, esto ocurría en un escenario de tendencias decrecientes de los precios en oro y de su simultánea elevación en plata ${ }^{32}$.

De lo anterior derivaba un mayor consenso en el gobierno porfirista sobre la idea de que la plata ya no podría recuperarse. Más aún, se había convertido en un factor que perturbaba el desarrollo alcanzado. Cada vez más se constataba como a "cada peldaño que bajaba de valor correspondía un aumento de su producción y perdía con celeridad sus caracteres de metal precioso para conservar sólo sus usos industriales" ${ }^{33}$. En este escenario, la extendida idea de cerrar minas para provocar escasez y posteriores revalorizaciones, carecía ya de sentido; sólo provocaría que las minas cerradas en Estados Unidos evaluaran reabrir. Por lo demás, en un juego de explicaciones reflejas, parte del auge productivo mexicano del final del XIX se debía al cierre de las minas norteamericanas. Esto era algo que se había entendido lentamente y cuyos costos no se habían querido admitir en razón de impulsar un modelo de crecimiento económico rápido, de tintes proteccionistas y sesgos favorables a los exportadores, que ahora también resultaban afectados.

\section{Elasticidad y reserva; otros problemas de cálculo de la plata}

Como se señaló anteriormente, la última década del XIX presenció una creciente perdida de mercado del peso en Asia (donde históricamente se demandó más moneda mexicana $)^{34}$. Al comenzar el siglo $\mathrm{xx}$, las posibilidades de exportar plata se contraían con fuerza; algo que constató la Comisión de Cambios Internacionales que viajó a Europa precisamente con el propósito de incrementar las exportaciones argentíferas.

Esta pérdida de competitividad del peso ha sido objeto de interpretaciones opuestas. Schell considera que al adoptar el patrón oro México se privó de una moneda elástica y apropiada a las necesidades de sus economías regionales ${ }^{35}$. Además, el nuevo patrón habría acelerado la dependencia económica respecto a los mercados internacionales y sincronizado los ciclos económicos mexicanos con los estadounidenses; lo que, para él, se evidencia con la crisis bancaria de 1907.

La anterior conexión causal es polémica, de Schell nos interesa más su alusión a la pérdida de flexibilidad monetaria causada por el ingreso en el patrón oro ${ }^{36}$. En su opinión, la historiografía desestimó el valor de las exportaciones de pesos por su

32 Casasús incorporó el cálculo de la depreciación — respecto al oro- contrastando "precios índice" de una canasta de bienes de consumo. Schell (2001) observa que "el poder de compra de la plata en relación con otras mercancías (distintas al oro) perdió poco en Europa y realmente se incrementó en América"; algo que habrían aprovechado los acaudalados importadores mexicanos que accedían a créditos internos relativamente baratos.

33 La Semana Mercantil, (1902), junio 20, n. ${ }^{\circ}$ 42, 2. ${ }^{a}$ época, año XVIII.

34 Para otros detalles y factores competitivos, véase Schell (2001).

35 Schell (1996).

36 Sin embargo, en Anaya (2002b) mostramos que ésa crisis no fue causada como Schell aduce. 
valor intrínseco (como mercancía-plata), que - al depreciarse la plata- se intercambiaban por una menor cantidad de mercancías u oro. Mientras no ocurrieran los reajustes de las autoridades, la diferencia entre el deprimido valor intrínseco y el alto valor facial del peso podrían implicar un cambio de preferencias entre los importadores, que podrían encontrar más rentable adquirir plata en pasta que moneda nominalmente cara. Éste último fenómeno es registrado por Mussachio, quien, con criterio contrapuesto al de Schell, observa que el peso “tenía muy malas expectativas como mercancía" y no ofrecía flexibilidad para la circulación nacional. Afirmación ésta última que intenta respaldar citando la escasez de moneda de plata a lo largo del siglo XIX y la "fácil aceptación de los billetes bancarios". Mussachio incluso agrega, que sólo el 5\% de la producción de plata era retenida en México hacia 1908.

Concuerdo con Mussachio en que la plata tenía "malas expectativas como mercancía" pero no creo que sus premisas (escasez de circulante-plata y aceptación de billetes bancarios) respalden bien su tesis. Más aún, de la investigación de Cerda se podría derivar lo contrario, que había sobreoferta de circulante a finales del siglo XIX. Además, sobre a la aceptación de los billetes bancarios se puede afirmar que era un proceso tardío y no ajeno a vacilaciones que continuarían —en menor gradoluego de la desmonetización de 1905 y en contra de lo supuesto por defensores del gold standard. Y es aquí donde nos parece que descansa un punto clave poco explorado del análisis de la reforma de 1905 y de sus límites para construir un sistema flexible o combinado de pagos anclado aún en una base metálica ${ }^{37}$. Desde luego, hay que señalar que el público tenía confianza en el circulante fiduciario gracias no sólo al respaldo metálico, sino también al del establishment porfiriano, que hacía creíbles los compromisos contractuales y las obligaciones de los bancos emisores.

Cabe advertir que la aceptación del circulante fiduciario no fue un proceso lineal y ascendente, sino uno de altibajos, en el que existía un desplazamiento de los billetes de los bancos provinciales por los que gozaban de circulación nacional (Londres y México y Nacional de México). Este proceso de concentración se debía a privilegios legales, al abuso de prácticas contables y a que el segundo actuaba como un banco de gobierno ${ }^{38}$. Resulta indicativo de ése desplazamiento el proyecto de emitir un billete provincial único con la finalidad de contener o al menos disminuir los onerosos costos de transacción que suponía la deficiente circulación fiduciaria interregional ${ }^{39}$. Al final, el proyecto sólo fue papel entintado. Seguramente conoció

37 Un sistema distinto era el norteamericano que respaldó originariamente la emisión de billetes bancarios en bonos del tesoro federal. Ciertamente estos bonos tenían como respaldo último una reserva metálica, sin embargo resulta importante reflexionar el dinamismo del sector bancario norteamericano desde esta variable.

38 Ludlow (1985).

39 Véase, Narciso Miranda, Director Gerente del Banco de Jalisco, a Limantour, junio 12, 1905, Fondo CDLIV, R. 33, AHC. Desde este otro ángulo debe leerse la expresión de Gurza (1905), relativa a que fuera "letra muerta" el precepto legal que restringió a los "billetes de los Bancos de los Estados una circulación local solamente". 
obstáculos institucionales y políticos, además que - para instalarse- debía salvar el ascendente peso relativo del Nacional, cuya fuerza lo hacía valorar la posibilidad fusionar el de Londres y México ${ }^{40}$. Es plausible que las razonables dudas de Limantour sobre la solidez de varios bancos provinciales importantes (que un par de años después pondrían a prueba al sistema bancario) también afectaran negativamente ese proyecto; como también lo hacía la falta de una bolsa de valores que cotizase y comerciara títulos de los bancos o la de aseguradoras que atenuaran los riesgos de operación en los negocios.

Así, aportar soluciones de mayor flexibilidad (o de medios generales de pago -moneda y billetes - que simultáneamente abarataran los costos de transacción y preservaran su valor) con solidez no era fácil y menos aún implementarlas en el corto plazo, dadas las peculiaridades del marco institucional bancario. En contraste a lo anterior, poca atención se ha prestado a uno de los corolarios de la reforma monetaria: la restricción explícita a ampliar el número de bancos de emisión ${ }^{41}$. Una medida que además de elevar las barreras de entrada al sector y enfatizar su carácter elitista, reafirmaba la coalición de intereses con el Estado porfiriano. Un efecto natural fue la mayor concentración del ingreso que, a su vez, reforzaba los bajos niveles de integración de la economía e imponía barreras adicionales en otros ramos industriales por la posibilidad de gozar o no de crédito, algo íntimamente relacionado con la pertenencia a un directorio bancario ${ }^{42}$. La segmentación se exacerbaba por la mencionada norma del descuento sobre billetes de Estados diferentes al del emisor local, pues la veintena de bancos emisores estatales frenaba recíprocamente su circulación, mientras la de los dos emisores nacionales la eludía ${ }^{43}$. Otra manifestación desatendida de la problemática son las altas denominaciones que tenían las emisiones de billetes y que probablemente retroalimentaban las deficiencias ${ }^{44}$.

40 Véase, correspondencia E. Noeltzin-Limantour, 1905, Ibíd.

41 Decreto que reforma la Ley de Instituciones de Crédito, 13 de mayo de 1905, art. 5, Secretaría de Hacienda y Crédito Público, Legislación Bancaria (I), México, 1957, p. 103.

42 El autopréstamo o crédito relacionado era la pauta dominante en la banca mexicana, por lo que usuarios externos o accionistas minoritarios rara vez accedían a créditos que les dieran la posibilidad de escalar sus negocios a niveles importantes. Lo mismo pasó en una etapa temprana en Estados Unidos, sin embargo la mayor densidad o número de agentes facilitó el acceso a esos actores pequeños. Lamoreaux (1996).

43 A lo que se intentó responder con el fracasado intento de crear un billete único y con una suerte de Clearing House, el ya mencionado Banco Central Mexicano, de pocas facultades regulatorias.

$44 \quad$ En la ley bancaria de 1887 se llegó a restringir el establecimiento de sucursales o corresponsalías en la capital de la República, lo que evidenciaba la influencia política de los bancos privilegiados y explica parcialmente el festejo con el que se saludó al Banco Central Mexicano hacia 1904; véase Gurza (1905), p. 50. Trabajos como el de Douglas (1998) muestran la importancia de las denominaciones altas, a las que muy difícilmente tenían acceso incluso los estratos medios de las poblaciones urbanas. A lo largo del porfiriato el proceso de penetración financiera en estratos urbanos fue lentísimo; la mayoría de la población (predominantemente campesina y, en mucho menor medida, obrera) no accedía a los servicios financieros formales, por lo que si requería de "crédito" debía recurrir al empeño o al usurero. 
En consecuencia, no existía un canje de equivalentes ágil sino uno de aceptación bajo tipos oscilantes de descuento (fluctuaba del 2 al 3\%); lo que ocurría también en la conversión por metal. Este funcionamiento gravoso (incluso sin considerar los costos de trasladar el metal para respaldo de operaciones) fue motivo de quejas reiteradas por los directorios de los bancos provinciales. Por otra parte, también conducía a que aprovechando los bajos grados de supervisión gubernamental, fuera común - entre los bancos - la práctica de fingir reservas ${ }^{45}$. Las prácticas ilegales para reducir costos de transacción eran comunes y se ligaban, por ejemplo, a recurrir a innovaciones creativas cuando la Secretaría de Hacienda intentó regulaciones más estrictas. En tal tesitura, el Banco Oriental fundó su "compañía bancaria" (institución similar al free banking norteamericano) para evadir el control gubernamental. Esa nueva compañía, El Descuento Español, tenía por objeto comerciar con el dinero de su principal con sus agentes emisores relacionados (el de Oaxaca y el de Chiapas). Además, como se fundó con capital depositado en su principal, es razonable inducir que el "depósito" fue una ficción contable ${ }^{46}$. De estas prácticas e "innovaciones" se pueden deducir más dudas razonables sobre el dinero que realmente circulaba y pueden respaldarse no sólo en prácticas abusivas o en cosmética contable, sino también en la deficiente intervención ejercida por las autoridades.

Desde luego, esos efectos aparecen subestimados en los datos oficiales del respaldo metálico dado al circulante fiduciario (Gráfico 1). La imagen nos permite hacer dos observaciones particulares y una general. La general hace referencia a las dificultades para aclarar suficientemente la relación entre los billetes circulantes y su respaldo (en los dos tipos distintos de metal). Las particulares enuncian motivos por los que el gráfico requiere ser interpretado con reservas. En primer término, porque si bien entre 1900 y 1904 las proporciones entre billetes circulantes y metálico en plata se satisfacían holgadamente (la ley estipulaba una relación de 50\%), lo hacían sobre la base de una depreciación acumulada del valor real de la plata; por esto, se trataba sólo de un cumplimiento nominal. En segundo lugar, porque al introducirse el patrón oro, la proporción del activo se redujo a sus montos mínimos y en los años 1906, 1908 y 1910, como se observa, no fue satisfecho ${ }^{47}$.

45 Anaya (2002b). La práctica de que accionistas de un banco lo fuesen de otros multiplicaba la posibilidad de efectuar créditos relacionados y era un modo informal de reducir esos costos de transacción.

46 Gamboa (2003). En todo caso funcionaba como un subsistema que buscaba disminuir costos de transacción.

47 Adicionalmente, el renglón de depósitos también reportó "saltos bruscos" en mayo de 1905 y julio de 1908 debidos a que el Banco Nacional de México en la primera fecha y el de Londres y México en la segunda, registraron depósitos en las partidas "depósitos y cuentas corrientes a la vista" y "depósitos a la vista a plazo no mayor de tres días"; cfr. Gómez (2001). Al parecer era un artilugio contable para diluir la estimación real del pasivo. De hecho el aplazamiento de la exigibilidad de los depósitos (a tres días) significaba una novedad en la reforma. Lo que añade razonabilidad a nuestra duda sobre la tendencia deficitaria en el respaldo global del sistema; que afectaba de manera heterogénea y diversa a cada banco en particular. 


\section{GRÁFICO 1}

RESPALDO METÁLICO A LA CIRCULACIÓN FIDUCIARIA

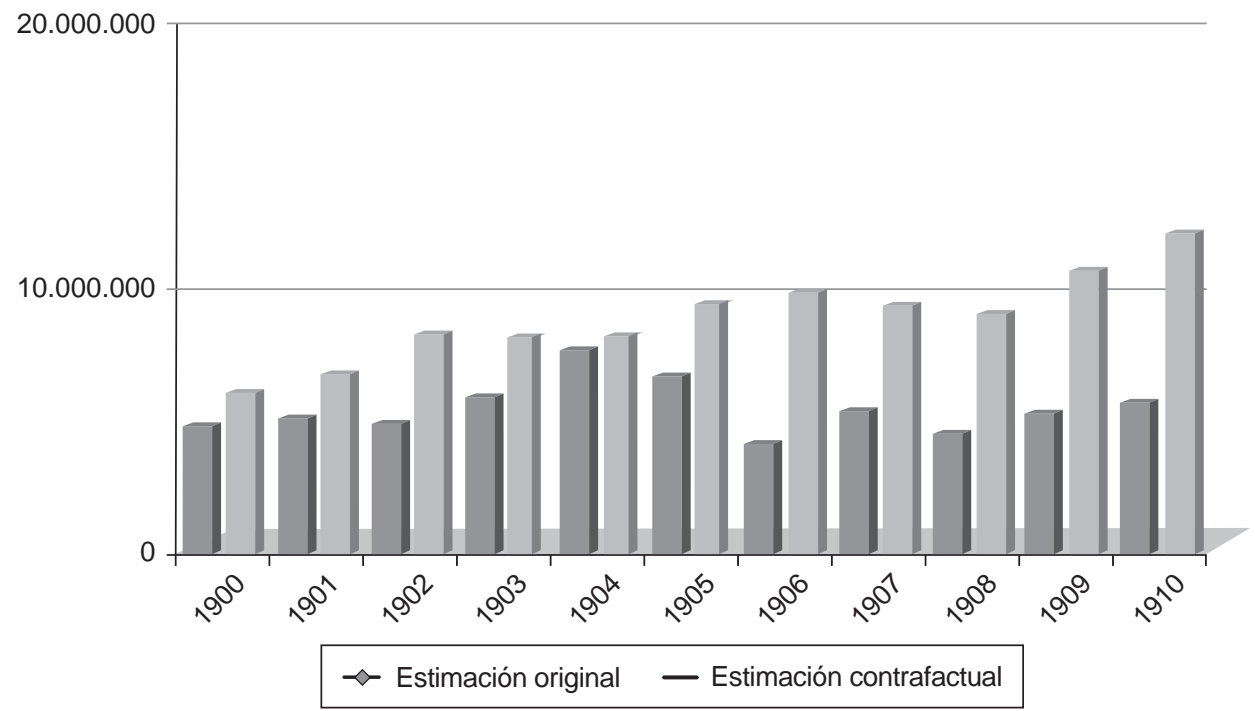

Nota: metálico y billetes se expresan en pesos mexicanos. Hasta 1905 las sumas respaldadas se hacen en plata y a partir de 1906 se registra en el nuevo sistema monetario de "Gold Exchange Standard".

Fuente: Memoria de las Instituciones de Crédito (1900 a 1910), México, Secretaría de Hacienda.

Si por mero ejercicio contrafactual descontáramos un $10 \%$ al respaldo metálico por concepto de prácticas de cosmética contable ${ }^{48}$ y cumplimientos leguleyos del "numerario en caja", sería más evidente que la proporción de billetes sin respaldo aumentaba, creando otro factor de inestabilidad monetaria. Si bien la hipótesis de un descuento del 10\% es arbitraria, no es alta ni está fuera de lugar, pues los inspectores de bancos denunciaban continuamente esa práctica a Limantour ${ }^{49}$. Para prevenirla se introdujeron los depósitos a plazo y el $4 .^{\circ}$ considerando del citado decreto de mayo de 1905 que reformó varios artículos de la Ley General de Instituciones de Crédito, que señalaba:

"es tiempo ya de hacer desaparecer la irregularidad que ahora se comete, de que en los Cortes de Caja y Balances mensuales de cada Banco, los saldos que proporcionan las Sucursales y las Agencias que se encuentran en las condiciones determinadas por la

\footnotetext{
48 Por ejemplo, estados de cuentas al revés, es decir, estados de cuenta que son prefigurados o cuyos resultados no se derivan de las operaciones de saldar ingresos, egresos, primas de riesgo, quebrantos, etc., para intentar reflejar de modo fehaciente el estado del negocio.

49 Algunos ejemplos en Anaya (2002b).
} 
circular del 5 de agosto [1904] ..., se refieran a fecha anterior a aquella en que se practica en la Casa Matriz, y que es preferible á que subsista esta irregularidad, la demora de unos cuantos días en la formación y publicación de los Balances de los Bancos" ${ }^{\prime 50}$.

¿De dónde procedía esta diferencia temporal de los balances de sucursales y agencias con respecto de sus casas matrices? Sencillo, de la práctica advertida de fingir reservas. Reportes confidenciales de los inspectores de instituciones de crédito la describen ampliamente, coincidiendo en señalar que los traslados de metal de los bancos se efectuaban para cubrir solo en forma el requisito de arqueo practicado por los inspectores mensualmente. Así, aunque el artículo $6 .^{\circ}$ de la ley reglamentaria les otorgó mayores poderes, preservó las inspecciones bajo la discreción del secretario. Esto sugiere, en Limantour, un deseo de supervisar más atentamente el estado de los bancos; pero se trataba de un mero deseo, pues las posibilidades de quebranto que disponían los banqueros defraudadores eran más amplias y sofisticadas que la capacidad de supervisión de las autoridades e incluso aquellos contaron con la complicidad y corrupción de éstas; al menos así lo indican los fraudes ocurridos en el Banco Yucateco y el Minero de Chihuahua en $1907^{51}$. Ambos fueron verdaderos escándalos políticos y sociales de la época y causaron una caída de las reservas metálicas en 1908, además de otros impactos sobre el resto del sistema bancario.

En 1913, con circunstancias políticas distintas, se redujo a un 33\% el respaldo metálico (lo que por cierto, era un antiguo anhelo), considerándose que el tránsito era natural, aunque desde otro ángulo parecía legalizar el irregular comportamiento de muchos bancos. La reducción se recibió con desconfianza, como ocurrió en Yucatán en 1907, pues se temió la inconvertibilidad y la depreciación de los billetes que finalmente llevaría al colapso del sistema. Después de todo, el problema de la convertibilidad no es un asunto de grados, sino de confianza; mientras existe la proporción puede ser un asunto menor, pero cuando desaparece la única válida es el $100 \%$.

\section{El circulante}

Como hemos visto, la estadística monetaria no fue una preocupación de la pax porfiriana. Críticos de la época como Toribio Esquivel Obregón resaltaron el poco ade-

\footnotetext{
50 Secretaría de Hacienda (1906), p. 129 y ss. Dicho considerando se transliteró, pues en la redacción del artículo $4 .^{\circ}$, no apareció toda la sinceridad del considerando.

51 Barrera (1997), Arce (1911) y correspondencia del Gobernador de Yucatán, Enrique Muñoz Arístegui, con Limantour, CDLXIV, CEH-CARSO, r. 49.
} 
lanto estadístico que incorporó el clan de "los científicos" al conocimiento de la economía. Connotados representantes de éstos, como el citado Casasús o Enrique Creel (secretario de Gobernación y embajador en Washington), Luis Camacho (agente financiero de México en Londres) y Eduardo Meade (director del Ferrocarril Nacional), harían suya la crítica en materia del dinero circulante al admitir, en la Comisión Internacional de Cambios de la República Mexicana, la falta de datos fiables sobre las exportaciones de plata: "no es fácil saber con exactitud cuanta plata se necesita para la circulación interior, porque la acuñación es constante y porque la exportación de pesos mexicanos trastorna las bases de la circulación interior" ${ }^{\prime 52}$. Por esto debió ser arbitraria la estimación de un circulante de 106 millones de pesos en 1903 y de 110 en 1905, cuando se efectuaría la reforma. El asunto cobró relevancia para el establishment porfiriano por su familiaridad con teorías monetarias para las que la cuantificación era crucial y porque desconocerlo implicaba calcular erróneamente los costos que supondría transformar el sistema a oro.

La citada Comisión de Cambios representaba las nuevas preocupaciones intelectuales y en particular de la teoría bimetálica sostenida por el Crédit Lyonnais. Aquí, la limitación o expansión del medio circulante tenía una influencia tan fuerte sobre los cambios internacionales "que se sustraía a otros factores que aparentemente deberían influir y aún determinar los cambios internacionales". Para el Crédit los cambios internacionales:

1. subían cuando había superabundancia de moneda;

2. bajaban cuando se presentaba una escasez relativa;

3. el mal empleo gubernamental de los créditos no alteraba el resultado de esas leyes;

4. tampoco eran alteradas por un desequilibrio de la balanza comercial.

Su teoría contemplaba preceptos singulares para la plata; sosteniendo sus afirmaciones 3 y 4, con el matiz de que la moneda plata no tendría más valor en oro que la parte alícuota de valor en oro que contuviese. Y añadía que, "el valor en oro de la moneda-plata podía elevarse si se limitaba la circulación a las necesidades interiores y a la proporción natural [cursivas nuestras] sobre la base de población" ${ }^{53}$.

En la Comisión surgió el convencimiento de que el comportamiento con patrón oro o plata era similar y, por tanto, era su escasez o abundancia, lo que determinaba

52 E. Creel, L. Camacho y E. Meade a E. Lefébvre, Chef des Études Financières au Crédit Lyonnais, junio 27 de 1903, CEH-CARSO, CDLIV, r. 19.

53 Comission on International Exchange of the USA/Comisión de Cambios Internacionales de la República Mexicana Acta, No. 10, junio 22 de 1903, CEH-CARSO, CDLIV, r. 19. 
la baja o alza de sus cambios internacionales. De lo que derivaron dos puntos importantes: por un lado, limitar las acuñaciones para provocar escasez y revaluar la moneda y, por otro, crear un fondo regulador de la reserva. Si acaso no estuvieron convencidos de la teoría (que sistematizaba y derivaba en sentido radical ideas comunes en México), sí lo estaban de su instrumentación, puesto que los planteamientos concordaban con los objetivos que los llevaron a Europa. Éstos eran tres: 1) convencer a Francia (cuyas existencias argentíferas e inversiones internacionales eran muy importantes) de participar en un comité para la organización monetaria de China (el mayor consumidor mundial de plata); 2) promover exportaciones de plata mexicana y 3) estudiar instrumentos para disminuir las fluctuaciones de los cambios internacionales o procurar su "fijeza”. El primer objetivo suponía tanto la aceptación china como la participación de varios equipos de asesores internacionales que estudiarían el problema. La rentabilidad del segundo punto estaba asociada a la consecución del tercero.

A decir de la teoría asumida, debían considerarse las necesidades interiores y la "proporción natural" de población que la empleaba. Históricamente analizada, tal "proporción" podía ser todo, menos natural, pues necesariamente dependía de variables relacionadas con la historia de esas poblaciones: la integración interna de su economía, de los sectores líderes, de la rigidez de los medios de pago, de los hábitos de consumo, de la distribución de la riqueza, de los habitantes que accedían a crédito formal, del volumen de los negocios... e, inclusive, otras cualidades que determinan el comportamiento de los habitantes que son consumidores o productores. De cualquier modo, la Comisión mexicana dispuso de la información del Lyonnais para argumentar en favor de sus objetivos y dedujo de los datos del Cuadro 2 que las necesidades mundiales de moneda-plata permanecerían insatisfechas.

Hipotéticamente (es decir, abstrayendo la competencia que implicaba el patrón oro), sobre la base de esta información, las posibles acuñaciones futuras (E) deberían acercarse al tamaño de la población que las empleaba. Naturalmente, un problema importante e irresuelto del cuadro era establecer un cálculo para la comentada proporción natural. Resultaba arbitrario dividir el stock monetario (C) entre el tamaño de la población (B) para obtenerlo, de manera similar a como los datos aportados sobre acuñaciones y reacuñaciones dependían de políticas públicas, sistemas bancarios, los volúmenes de otros instrumentos de circulación monetaria, etc. Los cálculos sobre futuras acuñaciones también se veían necesariamente afectados por estas variables y por los efectos de las nuevas acuñaciones (D) sobre el stock (C). 


\section{CUADRO 2}

ESTADÍSTICA MULTINACIONAL: POBLACIÓN Y VECTORES DE ACUÑACIÓN ARGENTÍFERA HACIA 1903

\begin{tabular}{|c|c|c|c|c|c|c|}
\hline \multirow[b]{2}{*}{ Austria-Hungría } & \multirow{2}{*}{$\begin{array}{c}\begin{array}{c}\text { Población } \\
\text { (miles de } \\
\text { personas) } \\
\text { (B) }\end{array} \\
47.100\end{array}$} & \multirow[t]{2}{*}{$\begin{array}{c}\begin{array}{c}\text { Stock } \\
\text { monetario } \\
\text { plata* } \\
\text { (C) }\end{array} \\
80.000 .000\end{array}$} & \multirow{2}{*}{$\begin{array}{c}\begin{array}{c}\text { Proporción } \\
\text { natural } \\
\text { (C/B) }\end{array} \\
1,69\end{array}$} & \multicolumn{2}{|c|}{$\begin{array}{c}\text { Acuñación o } \\
\text { reacuñación de } \\
\text { nuevas monedas } \\
\text { de plata* (D) }\end{array}$} & \multirow{2}{*}{$\begin{array}{c}\begin{array}{c}\text { Futuros } \\
\text { presumibles } \\
\text { de acuñación* } \\
\text { (E) }\end{array} \\
4.000 .000\end{array}$} \\
\hline & & & & 3.500 .000 & & \\
\hline Bélgica & 6.700 & 23.300 .000 & 3,47 & - & & 500.000 \\
\hline Bulgaria & 3.700 & 3.200 .000 & 0,86 & - & & 100.000 \\
\hline Australasia & 5.500 & 6.100 .000 & 1,10 & - & & \\
\hline Canadá & 5.500 & 5.000 .000 & 0,90 & - & (a) & \\
\hline Cape Colony & 2.300 & 1.000 .000 & 0,43 & - & (a) & \\
\hline Gran Bretaña & 41.600 & 116.800 .000 & 2,80 & 3.400 .000 & & \\
\hline India & 295.000 & 485.300 .000 & 1,64 & 19.000 .000 & & \\
\hline Straits Settlements & 5.100 & 30.000 .000 & 5,88 & - & & 30.000 .000 \\
\hline América Central & 5.100 & 7.000 .000 & 1,37 & - & (b) & 200.000 \\
\hline Cuba & 1.600 & 1.500 .000 & 0,93 & - & (b) (c) & 1.000 .000 \\
\hline China & 330.100 & 750.000 .000 & 2,27 & 18.000 .000 & & 18.000 .000 \\
\hline Dinamarca & 2.600 & 5.900 .000 & 2,26 & $\begin{array}{c}\text { (integra al } \\
\text { siguiente) }\end{array}$ & & \\
\hline Noruega & 2.200 & 3.100 .000 & 1,40 & 266.000 & & 500.000 \\
\hline Suecia & 5.100 & 7.000 .000 & 1,37 & $\begin{array}{r}\text { (integra al } \\
\text { anterior) }\end{array}$ & & \\
\hline Egipt & 9.800 & 6.400 .000 & 0,65 & 230.000 & & 50.000 \\
\hline Finlandia & 2.700 & 600.000 & 0,22 & - & & \\
\hline Francia & 39.000 & 419.800 .000 & 10,76 & 180.000 & & 7.000 .000 \\
\hline Grecia & 2.400 & 1.500 .000 & 0,62 & & (b) & 100.000 \\
\hline Alemania & 56.400 & 207.500 .000 & 3,67 & - & & 5.000 .000 \\
\hline Haití & 1.000 & 2.500 .000 & 2,50 & & (b) & 100.000 \\
\hline Italia & 32.500 & 38.400 .000 & 1,18 & 100.000 & & 1.000 .000 \\
\hline Japón & 46.500 & 29.500 .000 & 0,63 & 7.650 .000 & & 5.000 .000 \\
\hline México & 13.500 & 106.000 .000 & 7,85 & 18.000 .000 & & 4.000 .000 \\
\hline Países Bajos & 5.100 & 56.000 .000 & 10,98 & 70.000 & & 200.000 \\
\hline Portugal & 5.400 & 34.100 .000 & 6,31 & 1.250 .000 & & 1.000 .000 \\
\hline Rumania & 6.000 & 800.000 & 0,13 & & (b) & 50.000 \\
\hline Rusia & 130.800 & 103.200 .000 & 0,78 & 7.650 .000 & & 5.000 .000 \\
\hline Serbia & 2.500 & 1.700 .000 & 0,68 & & (b) & 50.000 \\
\hline Siam & 6.300 & 193.000 .000 & 4,87 & - & & 500.000 \\
\hline \multicolumn{7}{|l|}{ Estados de América } \\
\hline del $s$ & 39.600 & 18.700 .000 & 0,47 & 3.200 .000 & & 3.000 .000 \\
\hline España & 17.800 & 173.700 .000 & 9,75 & 3.300 .000 & & 3.000 .000 \\
\hline Suiza & 3.300 & 10.700 .000 & 3,24 & & (b) & 100.000 \\
\hline Turquía & 24.200 & 40.000 .000 & 1,65 & & (b) & 100.000 \\
\hline Estados Unidos & 78.400 & 665.000 .000 & 8,48 & 3.160 .000 & (d) & $16.000 .000 \quad(\mathrm{e})$ \\
\hline Totales & .400 & 34.300 .000 & 02,83 & 88.956 .000 & & 106.000 .000 \\
\hline
\end{tabular}

* Pesos, relación plata-oro: 32/1.

C: montos de moneda de plata que el país sostiene como promedio anual; D: promedio de acuñación en los últimos 12 años; E: montos anuales estimados de plata que se comprarán en los siguientes seis años.

a: no hay información de reacuñaciones; b: no hay reportes publicados de acuñación ni de reacuñación; c: un sistema de acuñación podría ser establecido en el futuro cercano; d: sólo acuñación fraccionaria o subsidiaria; e: incluye acuñación para las Islas Filipinas.

Fuente: Comisión de Cambios Internacionales de la República Mexicana, Londres, 15 de junio de 1903. 
Además de objetivos diplomáticos y comerciales, la elaboración de esta síntesis se orientaba —en un uso doméstico- a estudiar el cambio de patrón monetario. Como en éste también eran previsibles oscilaciones en el tipo de cambio, había que fortalecerlo con un fondo de compensación que regulara excedentes, bajas y cambios de divisas internacionales. Este fondo sería operado por la Comisión de Cambios y Monedas que luego se convertiría en la Comisión Monetaria; la misma serviría en 1925 como plataforma para fundar el Banco de México. Otras de sus funciones serían remediar la escasez de circulante causada por alzas de tasas de interés, afrontar las crisis monetarias y la parálisis de los negocios, etc. Por esto el fondo se articulaba con la creación de reservas áureas en el extranjero, que facilitarían regular cambios internacionales y controlar oscilaciones del tipo de cambio. Así, el propósito fundamental del fondo - como pieza central de la reforma monetaria de 1905- era evitar "fenómenos de tirantez" y adecuar la masa monetaria a "las corrientes naturales de circulación". La apuesta era que el modelo de funcionamiento sería exitoso porque "el mercado monetario era muy sensible y sería fácil dominarlo" ${ }^{\prime 54}$. Una facilidad plausible si se considera que el cambio de patrón suponía corregir la exportación de pesos mexicanos (ahora de valor nominal), lo que además facilitaría a las autoridades la estimación de las cantidades de circulante requerido.

\section{Instrumentar la reforma: ¿contracción o flexibilidad?}

Como se aprecia en el Cuadro 2, tomando una base alta de plata circulante en México (110 millones de pesos en 1903), se estimaron los cálculos de la reforma de 1905. Aquélla, o una cifra muy cercana, sería la base de la emisión de la nueva moneda, aunque ahora bajo un sistema de acuñación limitado. El punto importante de la limitación era la clausura de casas de moneda particulares; lo que por cierto afectaba el ideario liberal y el concepto de "buena moneda", al impedir su libre expansión respecto a su demanda, por ejemplo, como bien exportable en la esfera del comercio internacional. Así, la reforma no pretendía solo desmonetizar - o recoger las monedas en circulación para sustituirlas por otras de valor nominal—, sino que también buscaba una mayor regulación estatal de la masa monetaria. Esto refleja la prudencia con la que se ingresaba en el patrón oro. Mejor aún, en el Gold Exchange Standard, puesto que el sistema que adoptó México era el conocido como "el tercer sistema" (el monometálico y el bimetálico eran los otros dos) o "patrón cojo", pues conservaba la circulación obligatoria e ilimitada de monedas de plata (desmonetizadas y

54 Creel, Camacho y Meade a E. Lefébvre, Chef des Etudes Financieres au Crédit Lyonnais, junio 27 de 1903, CARSO, CDLIV, r. 19. 
restringidas en su acuñación) con las de oro. Si bien los efectos de éste patrón, combinado con la suspensión de las acuñaciones particulares, fueron diversos, el efecto perseguido de separar el valor comercial del metal y el propiamente monetario, se registró pronto ${ }^{55}$.

Era claro que el papel de los bancos sería muy destacado, pues del monto sobre el que se calculó la base monetaria, éstos conservarían más de la mitad: alrededor de 60 millones. Una cifra que cuadra bien con el sentido del Gráfico 1 para 1905, pero que, como se aprecia en los siguientes años (cuando los respaldos bajaban hacia los 40 millones de pesos oro y se expandía la emisión fiduciaria), se trataba de un cálculo muy optimista, que no satisfacía efectivamente (en su calidad de fondos de garantía) la cobertura de las emisiones ni los depósitos a la vista. El resto de los números confirmaba la relevancia de los bancos; la Comisión estimó en 30 millones las necesidades de pequeñas transacciones comerciales y en 20 los giros al exterior. Estos 20, dada la aludida sensibilidad del mercado monetario, serían regulados por el gobierno con una reserva de 10 millones de dólares oro, ya que al establecer un cambio del $200 \%$, en caso de requerirse la intervención gubernamental, esta reserva podía recoger excesos o sobrantes de flujo por el doble de su monto.

Estos eran los instrumentos diseñados por el gobierno mexicano desde 1903. Con la crisis de 1902 se abandonó la "fórmula de compromiso" con los sectores afectados por el cambio y la controversia en torno del ingreso en el patrón oro ${ }^{56}$. Incluso los sectores más recalcitrantemente platistas ya habían aceptado el cambio y aprendido la lección, aunque la percepción popular estuviese todavía muy lejos de asimilarlo. Entonces se definieron los medios técnicos que emplearía la Comisión de Cambios y Moneda para prevenir riesgos causados por reacciones negativas o por la propia aleatoriedad del mercado.

Las bóvedas del Nacional de México fueron las elegidas para resguardar el fondo de reserva que administraría la reformada Comisión de Cambios (que pronto se conocería como "Monetaria", por decreto de abril de 1905) ${ }^{57}$. A la Monetaria se le concedieron medios para ampliar los 10 millones originales, esperando que alcanzara sus objetivos y se convirtiera en un mecanismo alternativo de financiamiento gubernamental. A pocos meses de iniciada la reforma sobrevino un movimiento alcista de la plata, motivado por la guerra ruso-japonesa. La inesperada alza permitió salvar la temida escasez de oro que se advertía como un escenario posible al cambiar de patrón, y propició una rápida consolidación de la Monetaria, lo que —aunado a la tolerancia hacia el respaldo que efectivamente tenían los bancosevitó cualquier posible restricción de circulante. Felizmente, esta elevación del pre-

\footnotetext{
“Tendremos una verdadera moneda", festejó El Mundo, marzo 29, 1905.

Luna Argudín (1996).

Comisión de Cambios y Moneda (1909).
} 
cio de la plata suavizó la transición y la abarató, realizándola a un costo mucho más bajo del pronosticado.

En enero de 1906, el estado de la Monetaria era bonancible. En números redondos contaba poco más de 8 millones de pesos oro en reservas del Tesoro; 1.900 .000 dólares en Londres y 2.000.000 en Estados Unidos ("listos a venir cuando sea necesario"), como fondos reguladores en el extranjero (que se pensaban acuñar allá "con troqueles enviados de aquí"). La prensa festejó que esos números se hubiesen conseguido con gran reducción de costos y auguró una nueva era estabilidad ${ }^{58}$. Adicionalmente, se calcularon otros ingresos por 4 millones y otras existencias en "nuestra casa de Moneda" (400.000 dólares en pesos oro). A los 16.300.000 dólares que sumaban los montos anteriores se agregaba otra operación. Ésta tenía algunos vericuetos, pues la Monetaria vendió plata y adquirió reservas en moneda extranjera y barras de oro de los bancos Nacional de México Londres y México y Central Mexicano a cambio de certificados gubernamentales ${ }^{59}$; la diferencia entre su haber y su deuda en certificados le resultaba favorable por casi 150.000 dólares en pesos oro, depositados en las bóvedas del Nacional. Tal era, en conjunto, la circunstancia del fondo que regulaba las descompensaciones de la masa de dinero circulante en el país: certificados bancarios, depósitos en el extranjero, dinero por acuñar e ingresos futuros.

Un asunto distinto pero íntimamente vinculado, era el costo mismo de transformar del sistema monetario; éste se deducía de la diferencia existente entre el valor en oro de la moneda de plata en circulación y la cotización en oro de la nueva moneda. De ningún modo podría considerarse que dicho costo era fijo o estaba predeterminado. Al menos había dos opciones: elevar la unidad de valor de la moneda o asumir su depreciación. La primera implicaba un buen número de enredos (un período para readaptar precios, informar a la población de que su dinero "valía más" - convencerla y castigar a escépticos que aprovechaban el desconcierto-, etc.) difíciles de controlar por el gobierno. Como es sabido, la autoridad eligió la segunda vía, añadiendo un matiz: aceptó como nueva relación oro-plata, la de 1:32, la misma que implicaba una revaluación mínima, pues en los mercados centrales fluctuaba entorno a $1: 34$.

Sin expectativas de estabilización de la plata y con la elección de un modelo heterodoxo que debía ser probado en un plazo muy corto, no resulta fácil aclarar las razones por las que se adoptó la relación 1:32. Sobre todo porque al diseñar la reforma preexistía el temor a que los fondos asignados a la Monetaria no fueran suficientes - o resultara oneroso alcanzarlos - para estabilizar los cambios internacionales en el corto plazo. La elección asumía un riesgo adicional que se creía controlable

\footnotetext{
$58 \quad L a$ Semana Mercantil (1906), enero 8, 2. época, año XXII.

59 La Semana Mercantil (1906), febrero 5, 2. ${ }^{a}$ época, año XXII.
} 
enrareciendo la moneda; algo que no sólo procedía de una voluntad política, sino del hecho, simple y llano, de no haber oro suficiente. De aquí que lo más importante fuera el trabajo de consolidar los fondos de la Monetaria. Fue en dicha circunstancia que la tendencia alcista de la plata dio un enorme respiro a la transformación monetaria mexicana.

Los hechos fueron mejores que los más favorables escenarios, pues la ola alcista abarató la formación del fondo regulador y posicionó a la moneda incluso ligeramente por debajo del punto de equilibrio arbitrariamente fijado. A decir de Pablo Macedo, alto funcionario de la Monetaria, "anticipó los hechos", permitió cambiar "en pocas semanas más de 15 millones de pesos de nuestro stock monetario por oro". Esto es, un 50\% más de lo originalmente proyectado para un plazo mayor: algo impensable al momento de diseñar la reserva. Macedo explicó que "sin el alza", el fondo igualmente se hubiese consolidado sólo que con el transcurso de "3 o más años". El golpe de fortuna hizo que la reforma monetaria entrase en "su período práctico" y se planteara como un éxito rápido. La Semana Mercantil calificó el suceso como "quizá el más conspicuo de todos los que registra nuestra historia económica". Sin embargo, el éxito de la Monetaria no se correspondió con los respaldos del sistema bancario, que administraba más del 50\% de las reservas de un modo muy "liberal" y dos años después entró en una secuencia de pánicos que encarecerían el poco crédito existente, contraerían la oferta monetaria y acentuarían el estancamiento de la economía.

\section{Conclusiones}

Adoptando el modelo del "tercer sistema", México entró forzado, tarde y "cojeando" en la era del gold standard. Esta tardía reforma aporta una experiencia sugerente para la historia monetaria de los países emergentes. Revela las contradicciones de un proceso de modernización rápido, asociadas con la debilidad de una economía dependiente de una canasta pequeña de bienes de exportación. En contraste al declinante e inestable estado del otrora prestigiado peso mexicano de plata, la gerontocracia autoritaria porfiriana lucía suficientemente fuerte para dotar de credibilidad a los compromisos internacionales del país. Hasta el final del siglo XIX, el patrón plata resultó útil para impulsar una política económica que protegía la producción de bienes domésticos, alentaba las exportaciones y facilitaba una recaudación fiscal que permitía presupuestos más equilibrados, cubrir el servicio de la deuda y atraer capitales externos. Sin embargo, desde la década de 1890, la caída de la plata acentuó sus efectos negativos sobre el servicio de la deuda y las distorsiones económicas, e incubó un proceso inflacionario que, además de ensanchar la desigualdad entre los actores económicos, debilitó al fragmentado mercado interno. 
Al ser adoptado por las principales economías mundiales, el patrón oro apareció como la opción más importante de estabilidad (o, de muy baja variación en términos de índices de precios, tipos de cambio y poder de compra) y predictibilidad. A pesar de las garantías que ofrecía y los problemas del patrón plata, su elección como modelo para el nuevo patrón monetario de México sería un proceso largo y discontinuo (sólo se maduró en 1903 y se instrumentó dos años después), por la confluencia de diversas razones: los viejos intereses del sector platero — cuya resistencia solo se desvaneció hacia el comienzo del siglo xx- y la compleja evaluación político-diplomática que formuló el gobierno porfiriano y en cuyo seno se debatió "teóricamente" el problema y se diseñó la política monetaria, contando con pocos instrumentos de análisis estadístico. Finalmente, el proceso se encontró con un gran golpe de fortuna, pues si bien el costo de la transformación y de crear un fondo de reserva inquietaban al gobierno, sería una inesperada alza de la plata lo que facilitaría la transición y permitiría presentarla como fruto de los estrategas mexicanos.

En la revisión de esta importante experiencia latinoamericana, la historiografía ha desatendido el hecho de que el ejercicio de administrar la mayor parte de la base monetaria correspondiera a los bancos emisores. Una banca que era un poco más "liberal" que los intelectuales liberales porfirianos no aprovechó el súbito e inesperado abaratamiento que significó el movimiento alcista de la plata al inicio de 1905 para imitar a la recién creada Comisión Monetaria y fortalecer así sus arcas. Por su parte, el Ministerio de Hacienda festejó el alza, adelantó en más de tres años los objetivos de consolidación de la Monetaria, pero nada hizo para mejorar sus controles sobre la actividad de los bancos emisores. Es probable que, en el caso de que esto hubiese sucedido o de que simplemente los bancos hubiesen acotado sus emisiones a las disposiciones legales, se hubiese presentado una contracción de la oferta monetaria. Pero la teoría no se cumplió y la reforma apenas revisó tímidamente sus abusos. Dos años después vino la prueba: debido a sus malas prácticas internas y a una contracción del crédito internacional, los bancos emisores de Yucatán, Chihuahua, Jalisco, Guanajuato, entre otros, mostraron que carecían del respaldo metálico suficiente y eran incapaces de afrontar sus pagos de acuerdo con la legislación. Esto anunciaba que la expansión fiduciaria precedente no era sino una burbuja. Anunciaba sus límites tanto como lo deseable que era la supervisión bancaria y el abaratamiento de los costos de transacción. Mostraba que con la reforma el sistema monetario no se había hecho más flexible a una situación de "tirantez" o contracción económica.

Tales relaciones problemáticas han sido desestimadas por la historiografía, incluso el trabajo de Cerda, quien liga el alza de la plata con un "contrabando de grandes cantidades de metálico al exterior" en 1905-1907, lo que habría producido una "escasez de metálico" que "obligó" al gobierno mexicano "a permitir a los ban- 
cos de emisión un impulso fuerte a la oferta monetaria de papel moneda"60. Esto último habría paliado la falta de medios de pago. Sin embargo, contrario a lo que él observa, ya existía antes de la reforma una conducta permisiva del gobierno hacia los bancos emisores. Además de que los datos de emisión de los tres años inmediatamente posteriores a 1905 no avalan su afirmación sobre la expansión fiduciaria, en el marco institucional de la banca hubo pequeños cambios hacia un mayor control de las garantías de emisión. Es posible que la conducta seguida fuera la tradicional y se optase por el contrabando en lugar de cumplir el precepto legal del respaldo, pero también es posible que no contaran con los medios ni siquiera para intentarlo. En todo caso, el sistema bancario no preparó sus arcas para converger con los propósitos de la reforma monetaria. Así, la permisividad o falta de vigilancia gubernamental, los abusos oligopólicos, las malas prácticas contables y el hecho de ser los verdaderos administradores de las reservas nacionales, facilitaban a los bancos expandir la oferta monetaria. Pero era una expansión con pies de barro que dio continuidad al fenómeno inflacionario incluso después de la adopción del patrón oro y que agravó el estancamiento luego de los pánicos bancarios de 1907. Fue inoperante para asegurar los medios de pago sancionados por la reforma.

De Escalona y Mussachio hay que rescatar la idea de que el ingreso en el patrón oro representaba un "sello de garantía de estabilidad" monetaria. El "sello" canceló los menguados beneficios marginales que daba la depreciación a los sectores exportadores; por cierto, los dos más dinámicos estaban en mal estado: la minería de plata (el más directamente afectado) y el henequén, perjudicado por un control monoxómico, malos contratos y un abusivo maridaje de intereses político-económicos ${ }^{61}$. De manera que el "sello" diluyó costos de oportunidad ya cuestionados y sentó las bases para modificar el modelo anterior de crecimiento. Sin embargo, sus efectos reales serían difíciles de evaluar: primero por lo cercanía de la crisis de 1907-1908 y, en segundo lugar, porque el estallido revolucionario trastocó para las siguientes dos décadas cualquier ciclo de estabilidad e hizo irrelevante cualquier "sello de garantía".

En balance, la deseable expectativa de estabilizar los cambios internacionales era apenas una promesa frente a los gravosos males que acompañaban al silver standard (incremento del costo de la deuda, contracción de las inversiones extranjeras, inestabilidad monetaria, lenta expansión del crédito, etc.). La estabilidad se alcanzó

60 Cerda (1997), p. 328. No podemos estar de acuerdo en que la ausencia histórica "de una banca central" fuera la causa por la que no se podía controlar la oferta monetaria y "por lo que la emisión de moneda crecía sin control alguno". Como hemos visto, los porfirianos prefirieron no ser dogmáticos y crear un fondo de regulación que atendía el que - en su percepción- era el punto clave a regular: los tipos de cambio sobre el exterior. Por otro lado, el carácter oligopólico de la banca porfiriana y el carácter de "agente principal" que tenía el Banco Nacional de México, lo convertía en un organismo de control sobre el que el gobierno porfiriano podía incidir.

61 Sobre los problemas del segundo producto de exportación mexicana, el henequén, véase Wells y Joseph (1996). 
en forma mediocre para el corto periodo de dos años. La atracción de capitales fue muy modesta y hasta cierto punto inercial. Habría además que compararla con los costos de la reorganización de los ferrocarriles, que incluyeron dividendos amplios a inversionistas externos ${ }^{62}$.

Uno de los puntos más debatidos por los diseñadores de la reforma fue la cuantía de los fondos reguladores. El cálculo fue arbitrario por falta de estadísticas adecuadas y por excluir de éste a la banca de emisión; al final, se proyectó en 10 millones de pesos oro y la coyuntura lo permitió subir a 15. La apuesta del nuevo sistema era aminorar problemas de cambios internacionales y, por tanto, reducir la exportación de los desmonetizados pesos. Esto dotaría de elasticidad a los medios circulantes y permitiría hacer frente a los posibles efectos de escasez de moneda derivados de la transición; es decir, permitiría reducir o ensanchar la oferta más o menos automáticamente, "según necesidades nacionales y bajo control de acuñación cuidando que en ningún caso haya superabundancia" ${ }^{63}$. Como vimos, es dudoso que estos objetivos se alcanzaran. Aunque velada, la inflación continuó y la contracción sobrevino al primer pánico bancario regional (Yucatán) y las dificultades de refinanciarse en el exterior.

No obstante, la inesperada reducción de los costos de transformación del sistema monetario mexicano redujo un obstáculo considerado importante y que había distraído a los comités "científicos" porfirianos al imaginar dificultades similares a las que Francia sorteó. Así, la transición mexicana sería más comparable a la alemana (por el costo-oportunidad del cambio de patrón) que a la francesa; aunque, claro, esto era imposible de ser conocido ex ante.

Hacia el comienzo de 1913, cuando se avizoraban los signos del colapso bancario y la destrucción del sistema monetario, Limantour recordaría en París, en forma nostálgica, la intervención que la Comisión Monetaria pudo hacer en la crisis del verano de 1907. Técnicamente, la operación sirvió y el sistema financiero fue rescatado, pero - como es sabido - el gobierno de Diaz ya no tuvo tiempo para restaurar el consenso de los actores económicos y, mucho menos, de las clases populares. En todo caso, el nuevo patrón monetario no probó ser un instrumento ágil o lo suficientemente flexible para remediar la contracción crediticia de 1908 y restablecer la estancada economía porfiriana. El diseño de lo que prometía ser una reforma monetaria moderna se abstrajo de la relevancia que tenía el sistema financiero para su éxito. Bajo el cambio formal de moneda, la experiencia mexicana muestra que las distorsiones presentes en su rápido y desigual proceso modernizador acotan la validez de postulados teóricos y obligan a un mayor acercamiento a la historia económica.

\footnotetext{
62 Grunstein (1994).

63 Creel, Camacho y Meade a E. Lefébvre, Chef des Etudes Financieres au Crédit Lyonnais, junio 27 de 1903 , en CEH- CARSO, CDLIV, r. 19.
} 


\section{Fuentes}

Archivo Limantour, Fondo CDLIXV, Centro de Estudios Históricos CONDUMEX.

Comisión de Cambios y Moneda (1909), Memoria de la Comisión de Cambios y Moneda que corresponde al periodo transcurrido de 1 de mayo de 1905 a 30 de junio de 1909, Tipografía y Litografía de Müller Hermanos, México.

Periódicos.

La Semana Mercantil.

El Economista Mexicano.

El Imparcial.

El Mundo.

The Mexican Herald.

\section{Bibliografía}

ANAYA, Luis (2002a): Colapso y reforma. La integración del sistema bancario en el México revolucionario, 1913-1932, México, Miguel Ángel Porrúa - UAZ.

-(2002b): “La crisis internacional y el sistema bancario mexicano, 1907-1909”, Secuencia, septiembre-diciembre (54), pp. 155-185.

-(2006): “Del Banco Alemán Trasatlántico al Banco Mexicano de Comercio e Industria. Sindicatos financieros internacionales al final del porfiriato, 1902-1927", en KUNTZ, Sandra y PIETSCHMANN, Horst (coords.), México y la economía atlántica. Siglos XVIII-XX. México, El Colegio de México, pp. 239-268.

ARCE, Gustavo (1911): El desfalco al Banco Yucateco. Alegaciones y constancias del proceso, y del juicio de amparo promovido por el defensor del c. Ignacio Duarte Escalante, Mérida, Imprenta de "La Revista de Mérida".

CASASÚS, Joaquín (1905): La reforma monetaria, México, Imprenta de Hull.

CARMAGNANI, Marcello (1994): Estado y mercado. La economía pública del liberalismo mexicano, 1850-1911, México, El Colegio de México - FCE.

CERDA, Luis (1991): “¿Causas económicas de la revolución mexicana?”, en Revista Mexicana de Sociología, UNAM, LIII, 1, pp. 307-347.

CONANT, Charles (1910): The Banking system of México, Washington, Government Print Office, Document 493.

COVARRUBIAS, Enrique (2000): La moneda de cobre en México, 1760-1842. Un problema administrativo, México, UNAM - Instituto Mora.

CREEL COBIAN, Alejandro (1976): Enrique C. Creel. Apuntes para su biografía, México, Prensa de Editográfica Guadalajara.

DOUGLAS, Duane (1998): Emisiones desconocidas de Papel Moneda Mexicano, México, S/E. 
EICHENGREEN, Barry y FLANDREAU, Marc (1997): The Gold Standard in Theory and History, London, Routledge.

ESCALONA, Ana María (1998): La entrada de México al patrón oro y el acceso de México a los capitales extranjeros, tesis de licenciatura, México, ITAM.

ESCOBAR, Antonio (2004): Desastres agrícolas en México. Catálogo Histórico. Tomo II (1822-1900), México, FCE.

FLANDREAU, Marc (1996): “The French Crime of 1873: An Essay on the Emergence", en The Journal of Economic History, vol. 56, diciembre (4), pp. 862-897.

FRIEDMAN, Milton (1990): “The crime of 1873", en Journal of Political Economy, vol. 98 (6), pp. 1159-1194.

GAMBOA OJEDA, Leticia (2003): “El Banco Oriental de México y la formación de un sistema de banca, 1900-1911", en CERRUTTI, Mario y MARICHAL, Carlos, La Banca Regional en México (1870-1930), México, Fondo de Cultura Económica, pp. 101-133.

GÓMEZ, Mónica (2001): Un sistema bancario con emisión de billetes por empresarios privados: el comportamiento del Banco Nacional de México en el proceso de creación de dinero, 1884-1910, tesis de doctorado, El Colegio de México.

GRUNSTEIN, Arturo (1994): Railroads and Sovereignity. Policy-making in Porfirian Mexico, Tesis de Doctorado, Universidad de California en Los Ángeles.

GURZA, Jaime (1905): Nuestros bancos de emisión, México, Imprenta Central.

HART, John Mason (2008): The Silver of the Sierra Madre. John Robinson, Boss Shepherd, and the People of the Canyons, Tucson, The University of Arizona Press.

HANRAHAN, Gene Z. (1985): The Bad Yankee. El Peligro Yankee. American Entrepreneurs and Financiers in Mexico, Chapel Hill, Documentary Publications, IX, vol. II.

KEMMERER, W. Edwin (1916): Modern currency reforms, The MacMillan \& Co, Nueva York.

-(1947): Oro y patrón oro, Buenos Aires, Editorial Sudamericana.

LAMOREAUX, Naomi (1996): Insider Lending: Banks, Personal Connections, and Economic Development in Industrial New England, Cambridge University Press, Nueva York.

LUDLOW, Leonor (1985): “La construcción de un banco: el Banco Nacional de México (1881-1884), en LUDLOW, Leonor y MARICHAL, Carlos, Banca y poder en México (1800-1925), México, Grijalbo, pp. 299-345.

LUNA ARGUDÍN, María (1996): “La reforma monetaria limantouriana", en Relaciones. Estudios de Historia y Sociedad, El Colegio de Michoacán, verano-otoño $(67 / 68)$.

MUSACCHIO, Aldo (2002): “La reforma monetaria de 1905: un estudio de las condiciones internacionales que contribuyeron a la adopción del patrón oro en México", Secuencia, enero-abril (52), pp. 99-127. 
RETI, Steven P. (1998): Silver and Gold. The political Economy of International Monetary Conferences, 1867-1892, Westport, Connecticut, Greenwood Press.

RIGUZZI, Paolo (2003): ¿Reciprocidad imposible? La politica del comercio entre México y Estados Unidos, 1857-1938, México, Instituto Mora - El Colegio Mexiquense.

ROMANO, Ruggiero (1998): Moneda, seudomonedas y circulación monetaria en las economías de México, México, El Colegio de México - FCE.

ROSENZWEIG, Fernando (1965): "Moneda y bancos", en COSIO VILLEGAS, Daniel, Historia moderna de México. El Porfiriato. Vida económica, México-Buenos Aires, Editorial Hermes.

RUIZ, Ramón Eduardo (1998): The People of Sonora and the Yankee Capitalists, Tucson, The University of Arizona Press.

SALVUCCI, Richard (1991): “The origins and Progress of US-Mexican Trade, 18251884: 'Hoc opus, hic labor est'”, Hispanic Historical American Review, 71: 4, pp. 697-735.

SCHELL, William (1996): “Money as Commodity: México's Conversion to the Gold Standard, 1905", Mexican Studies/Estudios Mexicanos, 12, pp. 67-89.

-(2001): "Silver simbiosis: Re-Orienting Mexican Economic History", Hispanic American Historical Review, 81:1, pp. 89-133.

SECRETARÍA DE HACIENDA Y CRÉDITO PÚBLICO (1903-1904): Memorias, México, SHCP.

-(1906): Leyes y Disposiciones relativas a la Reforma Monetaria, México, SHCP.

TORRES MEDINA, Javier (1999): De monedas y motines: los problemas del cobre durante la primera República Central en México, 1835-1842, tesis (M.A.), UNAM-FFL.

TORTELLA CASARES, Gabriel (1975): Los orígenes del capitalismo en España. Banca, industria y ferrocarriles en el siglo XIX, Madrid, Tecnos.

VILLEGAS REVUELTAS, Silvestre (2005): Deuda y diplomacia: la relación México-Gran Bretaña, 1824-1884, México, UNAM-IIH.

WALRAS, Léon (1896): “Théorie de la propriété”, Revue Socialiste, 24: 139, pp. 23-25, París.

WELLS, Allen y JOSEPH, Gilbert M. (1996): Summer of Discontent, Seasons of Upheaval. Elite politics and Rural insurgenxy in Yucatan, 1876-1915, California, Stanford University Press.

ZABLUDOWSKY, Jaime (1984): Money, Foreign Indebtedness and Export Performance in Porfiriat Mexico, Thesis Dr. Philosophy, Yale University. 